\title{
ANALYSIS OF START-UP ENVIRONMENT IN WROCLAW AND THE ROLE OF THE URBAN INFRASTRUCTURE IN DEVELOPMENT OF INNOVATION PROJECTS
}

\begin{abstract}
The study aims to analyze the start-up environment in Wroclaw and describe the role of the infrastructure in the development of innovation ventures. In her deliberations, the author deploys both the quantitative and qualitative research carried out in the period between December 2016 and August 2017 in cooperation with the Wroclaw Agglomeration Development Agency, (Agencja Rozwoju Aglomeracji Wrocławskiej S.A., ARAW). The results of the research constitute added value as this is the first study in Poland dedicated exclusively to Wroclaw start-ups. The author hopes to continue her research, hence the obtained data is dynamic in its nature.

Keywords: start-up, innovation, city, urban space, infrastructure, Wroclaw
\end{abstract}

\section{Introduction}

More and more innovation projects, i.e. start-ups, are beginning to emerge globally as well as in Poland. The solutions that they propose are highly likely to launch breakthrough innovations in various fields. Start-ups are perceived as drivers of economic growth. According to the forecasts of Deloitte, in 2023 the added value generated by start-ups may amount to as much as PLN 2.2 billion (Deloitte, 2016). This is strictly connected with the role that innovations play in fuelling a competitive economy. With this assumption in mind, economic strength on the long run will rely on two key elements: the number (development scale) of start-ups and their quality measured as the likelihood of success (the percentage of companies that are successful on the market). Given the aforementioned classification of economies, the strongest economy features a large number of flourishing start-ups. The strongest economies include the United States and Israel (inc, 2017). 
Whether a start-up will be successful hinges on several factors. According to Bill Gates, who analyzed 200 innovative companies from the perspective of business success factors, the key factors include: the idea behind a start-up, team (work, commitment), business model, financing and the moment of market launch (rozwijamy, 2018). One of the additional elements that cannot be overlooked is the available infrastructure understood as R\&D, cultural and social resources intended to foster the growth of innovation projects. The quality of the resources is to a large extent conditional upon the way in which the urban policy is pursued by local authorities and upon the approved course of development of the urban space management strategy.

In her study, the author analyzes the start-up environment in Wroclaw against the background of the existence of innovation ventures in urban space. The author elaborates on the role of the city's spatial planning method in the growth of start-ups. In her concluding remarks, the author proposes recommendations for the city based on the quantitative and qualitative research conducted in the period between December 2016 and August 2017 in cooperation with ARAW.

\section{Definition of the terms: start-up and infrastructure}

In the paper and in the aforementioned research alike, the author defines a start-up as a small entity (not necessarily a company in commercial terms), primarily (but not exclusively) operating in the field of new technologies.

Eric Ries, one of the major figures in the start-up sector, defines a start-up as follows: a start-up is a human institution designed to deliver a new product or service under conditions of extreme uncertainty. Against this background, the author's research refers to a start-up in a broad sense, without restricting it to the technological sector. This approach is elaborated upon in detail in the book entitled The Lean Start-up. How Today's Entrepreneurs Use Continuous Innovation to Create Radically Successful Businesses, recognized by New York Times to be of crucial significance for the understanding of start-ups (Ries, 2012).

Compared with other entities, a start-up is characterized by a higher level of risk, mainly owing to its operation in the sector of technological innovations. A higher risk is usually associated with a higher return on investment provided that the venture is successful.

According to an encyclopaedia entry (Great Universal Encyclopaedia, 1965), the infrastructure means the basic, underlying facilities and systems providing services necessary for the manufacturing sectors of the economy to function. The infrastructure can be split into economic and social. According to Ginsbert-Gebert (1976), the economic infrastructure means the physical basis associated with a specific area, which serves both production and consumption needs in a broad sense. It consists of facilities and institutions necessary for the economy and population to function (Dziembowski, 1966; Ginsbert-Gebert, 1971). The economic infrastructure includes facilities and systems providing transport, communication, power supply, irrigation, farmland drainage services etc. 
The social infrastructure refers to facilities, institutions and assets offering services in the area of law, safety, education, healthcare etc. When describing the role of the infrastructure in the development of start-ups, the author considers both meanings of this term, by analyzing the importance of the socio-cultural and institutional resources for innovation projects.

\section{Methodological assumptions}

The data shown in the paper was obtained in a research project divided into three stages, conducted by the author. The first stage consisted in gathering and analyzing the available data from secondary sources (the so-called desk research). On the basis of the gathered information, a quantitative survey, addressed to start-ups, was prepared and conducted under the second stage of the project. The third stage included qualitative research taking the form of individual in-depth interviews.

The quantitative survey was intended to provide possibly the most precise description of the start-up environment in Wroclaw. Thus, the survey included questions about the registration year, employment and industry.

The individual in-depth interviews added to the statistics. The purpose of the qualitative modules of the survey is to acquire information about topics that have hardly been examined so far. The qualitative research is an attempt to capture a hidden sense which offers a structure to what is said as opposed to what is actually done, as well as to explore, describe more specifically and systematize the real meaning of the discovered social phenomenon (Banister et al., 1994). This is of great significance if start-up entrepreneurs' genuine needs and expectations from the city are to be analyzed.

Both the quantitative and qualitative parts had separate and strictly assigned functions. The quantitative research was based on a survey composed of 16 main questions. In some questions, after choosing a 'yes' answer, the respondent was asked to elaborate on it or make an additional statement.

The respondents were recruited through five channels:

1) a Facebook event (FB);

2) mailing;

3) direct contact;

4) during a selected event-in this case a conference dedicated to start-ups, Start-up

Wroclaw: Evolutions in November 2016;

5) www.wroclaw.pl website.

The snowball method was deployed to recruit the target group. It is used if the surveyed population members are difficult to reach. In the method, the researcher looks for a few members of the surveyed population and then asks them to get in touch with their friends who are also members of the population (Babbie, 2007).

Ultimately, $\mathrm{n}=108$ start-ups took part in the survey, both registered and those operating without registration. It should be pointed out that the difference between the total number of respondents and individual numbers of answers to questions e.g. 
about the registration place or the registered office results from the fact that start-ups already in operation, but not registered yet were also admitted to the survey.

It was relatively difficult to define the target group for the research sample. As the notion of a start-up is not unambiguously defined (see Chapter 1 for details), the approach of Ries, an authority for the start-up sector, was assumed.

The qualitative part involved individual in-depth interviews with seven industry experts and start-up owners associated with Wroclaw. The interviewees were selected owing to their discernibly proactive approach in the start-up sector, as well as owing to their role of mentors and authorities for other representatives of innovation projects.

In the study, the author refers to the results of both quantitative and qualitative surveys. The former provide a better picture of the condition of start-ups in Wroclaw, while the latter are an attempt to define the role of the infrastructure in the development of innovation projects.

\section{Description of the start-up environment in Wroclaw}

A detailed analysis of the environment for innovation ventures in Wroclaw indicates that $71 \%$ of the start-ups were established in 2015 and 2016 . Hence, they are no more than three years old. 16\% were founded between 2013 and 2014, which means that they have been in operation in this form for three to four years. Until now, a business operating in the market for three or more years has been regarded to be a relatively stable enterprise in the European Union. In accordance with the above criteria, $16 \%$ of the start-ups have already been through the toughest period, and their offer can be considered to have been accepted by consumers.

Registration place and area of operation. Wroclaw is the key registration place for the start-ups (almost 99\%); more than half of them (almost 56\%) operate countrywide, while almost $40 \%$ carry on business on an international scale (including less than $4 \%$ in Europe). Almost one fifth of them indicate both Poland and other countries as their area of operation. What matters is that almost $14 \%$ of them carry on business globally, while only $12 \%$ of the start-ups are focused on the Wroclaw market.

Start-ups are established mainly by two people $(41 \%)$ or one $(36 \%)$ person. Almost a quarter of them have three to six founders. The businesses are most frequently established by males $(73 \%)$. In the other cases $(27 \%)$ one or two females were among the founders.

Over half $(53 \%)$ of the start-ups are sole traders, without any additional personnel. Less than 50\% (47\%) are registered as Polish limited liability companies, one third $(34 \%)$ are sole proprietors and $15 \%$ of the respondents are limited partnerships or operate in Academic Entrepreneurship Incubators (AIP). 34\% of the respondents employ one to nine people (microbusiness category).

Period of employment. The period of employment in the start-ups (in $82 \%$ of the cases) usually lasts from one to three years, which can be concluded from the registration period of start-ups. For $10 \%$ of the respondents the period 
of employment is longer and amounts to $4-9$ years. $50 \%$ of start-ups hiring personnel employ 1-5 females.

Start-ups are mainly engaged in technology (59\%) such as website services $(36 \%)$, applications (20\%) and ICT (3\%). Services in a broad sense rank second with $27 \%$. Other much less frequent types of operation include an R\&D lab, computer game development, telemedicine and digital learning. The predominant answer to the question about the industry in which start-ups operate (47\%) is 'other'. This answer comprises areas associated with technologies, such as nanotechnology, service applications, business platforms, software/computer games, electronic devices, biotechnology, products (diagnostic sets) and (diagnostic) services in healthcare, veterinary science, food quality, pharmaceutical products or Internet of Things, e.g. smart home, CAD modelling and 3D printing, consumer electronics, technology/ photography, dedicated mechanical and civil engineering or manufacturing of technological fillers. If the respondents failed to identify their industry in the survey, this may mean that the existing sector designations are insufficient. This may also mean that, according to the reports on jobs of the future prepared i.a. by Deloitte, almost half of the current jobs will cease to exist. This is also evidenced by the research discussed in this study. Slightly above one quarter of the respondents indicated e-commerce. $23 \%$ of the start-ups operate in business in a broad sense. $18 \%$ of the respondents operate primarily in education, other respondents prefer lifestyle and sports (17\% each). $12 \%$ of the respondents focus on health. Lifestyle, sports and health also affect the created products and are connected with building environmentally friendly attitudes.

A vast majority of the respondents (almost three quarters) finance their business activity with their own funds. As few as $11 \%$ of them indicated EU grants, $6 \%$ benefited from the venture capital and $3 \%$ received financial support from business angels or accelerators.

The main sales model is reselling (over one quarter of the respondents) or subscription (23\% of the companies) $21 \%$ of the companies indicated sales models such as B2B, sale of applications per event, sale of a product via a global reseller network, manufacturing model, sale of their own products via the internet (e-stores or online auction and shopping websites), sale of electronic modules with an integrated licence for a service or sale through their own sales team.

Start-up owners' perception of the innovative aspect of the offered product. $58 \%$ perceive the offered product as innovative, $42 \%$ developed an existing product on the market. The offer by start-ups is mainly addressed to individual customers, microenterprises and SMEs. It should be noted that the offer is also targeted at large businesses (56\%), multinationals (37\%), institutional clients (34\%) and NGOs (17\%). This is proved by the declared geographical area of operation for start-ups.

Over $70 \%$ of the start-ups are either at an early stage (41\%) with a very high operational risk, at the stage of growing sales profitability, or at an earlier stage $(33 \%)$, i.e. seed (the start-up already has a prototype of its own product or has already placed a finished product on the market).

Almost $40 \%$ of the surveyed businesses did not generate any income at the moment of survey. On the other hand, $62 \%$ of the businesses declared occasional or irregular income. Over the last six months since the survey, their income 
has increased from 20 to $50 \%$ for one third of the businesses, less than $20 \%$ for $38 \%$ of the businesses and over 100\% for one fifth of the businesses.

Over one third of the respondents indicate cooperation with higher education institutions/research centres/laboratories. Knowledge sharing and inspirations are considered to be a major driver for the development of start-ups. It should be stressed though that large companies (including multinationals) are more and more interested in a model of cooperation with start-ups. They consider this model to be an innovation and development method for the R\&D department.

\section{The role of the infrastructure for the development of start-up organizations in Wroclaw}

As a result of an analysis of the available reports checking the attractiveness of individual cities for investors, it can be stated that Wroclaw is a business-friendly place. Wroclaw not only boasts of dynamic growth, but it is also a good place to live in. This benchmark looms large on the list of "attractiveness" features evaluated by start-up owners from Wroclaw.

According to PwC's Report on Polish Metropolitan Areas 2015, Wroclaw was the most dynamically developing metropolis between 2005 and 2015. According to the results of the study Global Cities of Future 2016/17, prepared by fDi Intelligence, a specialist division from FT Ltd., Wroclaw ranks first among European medium-sized cities in terms of its strategy to attract foreign investment. The city's indisputable strengths include the aforementioned investment attractiveness, the improving infrastructure and the growing level of human capital. What distinguishes Wroclaw from other metropolises is the high quality of education and a valuable labour market.

In the 2017 Quality of Living ranking by Mercer Wroclaw holds strong in the top half of the list. It claimed $100^{\text {th }}$ place among 231 surveyed cities. This may be the result of the city's activity. The city gets involved in various events to promote its image on an international scale. In 2012, Wroclaw was one of the host cities for UEFA Euro 2012 and in 2016, it was the European Capital of Culture. The authors of the report see the following as major challenges for the city: improvement of public safety, improvement of public transport and increased social engagement of Wroclaw inhabitants (PWC, 2015).

The dependencies between the start-ups and the available infrastructure go both ways. On the one hand, the available infrastructure affects the development level of start-ups. On the other hand, a growing number of start-ups has a positive impact on the development of the entire urban infrastructure, which provides labour and cultural resources for innovative businesses. A growing number of start-ups means a growing demand for co-working space or HORECA establishments to enable both individual work and group meetings. Hence, the development of start-ups also involves increased employment in other retail and service establishments.

Start-ups promote working standards, which at the same time impacts the business culture; this is demonstrated by expert statements in qualitative surveys. 
Moreover, the existence of innovation ventures has a positive effect on the general image of the city, influences the space management method and attracts specific social groups.

Owing to the innovative nature of start-up organizations, they contribute to increased entrepreneurship in local communities. Their existence also affects the way in which urban policy is pursued; more and more frequently, cities offer programmes and tools to support innovation projects. Although start-ups are gaining more and more importance both for national and regional economy, they keep encountering typical issues and adversities which hinder growth such as infrastructure barriers.

In the qualitative survey, the respondents analyzed Wroclaw in detail from the perspective of its benefits and drawbacks as a city where an innovative business can be set up and run. The experts stressed the benefits, but also indicated areas with room for improvement.

Being a university city is Wroclaw's definite advantage. Owing to extensive academic resources, companies gain easy access to the talent pipeline. The experts are not unanimous as to the costs of hiring specialized staff. Some of them consider the costs to be relatively low, in particular compared to the United States, while part of them claim that it is difficult to hire staff. The position of the latter group of experts will be presented in the next part of the study, dedicated to areas for improvement.

The image of the city has a crucial impact on the selection of the place for running a business. Wroclaw boasts of having a good atmosphere which is conducive to creativity. This is a friendly, well-designed and 'green' city. It is perceived in this way by residents and newcomers alike. People are also part of the city's image. The way in which Wroclaw is perceived to a large extent up depends on them.

Wroclaw is an active city offering a broad range of initiatives dedicated to start-ups. The initiatives enable networking, which is of crucial importance for the development of innovation projects. The events organized in Wroclaw include Start-up Wroclaw: Meetup, Start-up Wroclaw: Evolutions, Geek Week (technology weeks during which various local groups interested in IT meet) or the Start-up Weekend.

Start-ups in Wroclaw can count on the support of selected institutions. The Wroclaw Technology Park (WPT) supports start-ups by office space lease at a favourable price. WPT offers the opportunity to rent laboratory equipment within de minimis assistance, i.e. for $20-40 \%$ of the market price. Moreover, the Lower Silesian Academic Incubator of Entrepreneurship (DAIP), a joint venture of WTP and 12 Lower Silesian higher education institutions, offer training courses. The positive aspects of cooperation between the start-ups and WPT have been stressed by one of the experts who is an active beneficiary of WPT's offer.

The initiative of the Wroclaw Agglomeration Development Agency (ARAW), a municipal company, is also highly appreciated. In cooperation with the Municipal Office, under the Smart City project, the company launches a number of projects addressed to Wroclaw start-ups, including regular events such as "Start-up Wroclaw. Evolutions" and industry meetings such as MeetUp or "Wroclaw Start-up. Beer". 
When evaluating Wroclaw from the perspective of running a business, the experts also indicated areas with room for improvement. When referring to the academic nature of Wroclaw, which is regarded to be an advantage, the experts admitted that a large number of graduates does not mean that it is easy to hire a qualified employee.

Not everyone is willing to run an innovative business with a higher risk of failure and a relatively lower salary compared with what multinationals can offer. Multinational corporations offer a safer and more stable environment compared to start-ups. Wroclaw has attracted a number of multinationals because the city's policy favours investments by large players. Hence, not everyone is attracted to start-ups.

What is more, a specific type of work in a start-up may be an issue; continuous learning, knowledge sharing, a flexible approach towards dynamic change, risk tolerance, creativity and an innovative look.

One of the entry barriers is limited access to office space. According to the report Hot or not - Demand analysis [on the office market] in Poland issued in March 2017 by JLL, Wroclaw is the third largest (following Warsaw and Krakow) office market in Poland. Permanent interest from the tenants makes the developers more active, which contributes to increased supply of office space in the city.

As mentioned before, what actually distinguishes the city is its ability to attract new investors such as Axiom Law, UBS, Red Embedded and Ryanair. Thus, the tenants in Wroclaw are increasingly active. The adequately developed office market is reflected in higher rental costs. As there are no reliefs for local businesses, beginning entrepreneurs with limited funds will find it difficult to find a good location for their businesses.

Although the respondents appreciate the role played by institutions which support start-ups (such as WPT, Wroclaw Research Centre EIT+, ARAW), they also point to issues related to their operation.

The main issue with WPT and EIT + is that these organizations are mainly engaged in the lease of space rather than in the whole landscape associated with running an innovation project. What is more, some procedures with WPT are overly complex and formalized, which has an adverse effect on the everyday operation of a start-up.

Another expert mentions formal barriers also with reference to the operation of ARAW. As he sees it, there is too much administration work at the Agency. The Agency is unable to respond in a flexible and dynamic manner because it is a city company bound by all the resulting procedures. Its operation makes sense when addressed to larger entities, but not really to start-ups.

Wroclaw lacks the infrastructure supporting start-ups. The city has neither a campus nor other similar places where it would be possible to study, share knowledge and exchange experiences. It should be emphasized though that Wroclaw is an active city where a lot is going on. According to the experts, there are still too few activities and events focused on start-ups. In the opinion of one of the experts, there are not enough meetings with international guests who are prepared and willing to invest in innovation projects. There are also not enough serious speakers ready to share their experiences. 


\section{Conclusions and recommendations for further research}

It seems that Wroclaw's infrastructure has great potential as regards the growth capacity for start-ups compared to other large cities in Poland. However, this requires certain steps to be taken. For example, Google Campus Warsaw can be a point of reference.

An adequate infrastructure involves pursuing a friendly policy related to the use of space for offices where industry consultations can take place. To this end, Wroclaw ought to allocate dedicated funds from the city budget. More places are necessary, where an office or an individual desk can be rented at an attractive price. An innovative bundle offer should be in place for start-up owners to rent flats accompanied by legal counselling and accounting services. This solution is offered i.a. by Clipster in Gdańsk and the Kielce Technology Park.

The city should actively support start-ups in knowledge sharing and networking i.a. by organizing meetings with authorities and decision-makers, e.g. from the USA, arranging expert consultations, organizing networking space (infrastructure adjustment). Creating a position of a start-up officer at the Municipal Office, in the role of an intermediary between city officials and young start-up owners, will definitely contribute to the exchange of knowledge.

Another way in which the city can support start-ups is the organization of thematic training sessions on the fundamentals of running a business, and administrative assistance. The city ought to take an active part in providing enterprises with basic education.

Closer cooperation with higher education institutions is strongly recommended. Liaising between various environments yields positive results since diverse approaches are introduced and added value is created. There must be trust between institutions and start-ups. A relationship of trust is built if the needs and expectations are clearly expressed by each party engaged in the dialogue. The city may bolster the achievements of individual start-ups by promoting them or publicizing their success stories. In this way, the city will contribute to information sharing and creating role models for other entities in the industry.

The city should also differentiate between various channels to reach start-ups. It is not enough to publish information on the website www.wroclaw.pl. Very few people visit it. Many more people visit Facebook. It seems to be a good idea to use social media in this context. Besides, information about events and projects can be provided during industry events. It is mandatory that the events should be really suited to the needs and expectations of start-ups.

The final message is primarily addressed to the representatives of the industry. Self-organization and facilitation of the start-up environment is a must. Also in this area, the city may actively support the activities of start-up owners, for example, by helping them use the available space in the best possible way.

The completed research forms a basis for continuing the analysis of the start-up environment. In order to make the research model more dynamic, the author suggests that the surveys should be carried out on a regular basis, with the use of a reviewed questionnaire and with more start-ups taking part in the survey. 
Hence, a valuable database will be obtained that will help analyse in detail the changes in the Wrocław start-up environment over the years.

\section{References}

Babbie, E. (2007), Conducting qualitative field research, In: The practice of social research (11 $1^{\text {th }} \mathrm{ed}$.). U.S.A., Thomson Wadsworth.

Banister, P. et al. (1995), Qualitative Methods in Psychology: A Research Guide, Open University Press, Buckingham.

Dziembowski, Z. (1966), Pojęcie infrastruktury i jej charakterystyka [The Concept and Characteristics of Infrastructure], Miasto [City], 2, p. 23.

Ginsbert-Gebert, A. (1971), Infrastruktura i jej rola w rozwoju miast [Infrastructure and Its Role in Urban Development], Miasto [City], 9.

Ginsbert-Gebert A. (1976), Infrastruktura i jej rola w rozwoju miast i wsi [Infrastructure and Its Role in Urban and Rural Development], Research Works. Oskar Lange Wroclaw University of Economics, 99(121), p. 8.

Ries, E. (2012), The Lean Start-up. How Today's Entrepreneurs Use Continuous Innovation to Create Radically Successful Businesses, Crown Publishing Group, Division of Random House Inc.

Wielka encyklopedia powszechna [Great Universal Encyclopaedia] (1965), vol. 5, PWN, Warsaw, p. 54.

\section{Reports}

Deloitte (2016), Diagnoza ekosystemu start-upów w Polsce [Diagnosis of Start-up Ecosystem in Poland], Deloitte Report, Warsaw.

fDi Intelligence (2016/17), Global Cities of Future 2016/17, Financial Times Group. Available from www.fdiintelligence.com/Rankings/fDi-s-Global-Cities-of-the-Future-201617-the-winners [Accessed 5 February 2018].

jll (2017), Hot or not - Analiza popytu na biura w Polsce [Hot or not - Analysis of Demand for Office Space in Poland]. Available from http://www.jll.pl/poland/pl-pl/Research/ Hot_or_not_2017_PL.pdf [Accessed 20 March 2018].

mercer (2017), Quality of living. Available from www.mercer.com/newsroom/2017-quality-of -living-survey.html [Accessed 20 March 2018].

pwc (2015), Report on Polish Metropolitan Areas 2015. Available from https://www.pwc.pl/pl/ pdf/miasta/raport-o-metropoliach-wroclaw-2015.pdf [Accessed 20 March 2018].

\section{Online sources}

inc (2017), The Top 10 Global Start-up Hubs of 2017. Available from www.inc.com/zoe-henry/ ss/top-emerging-start-up-hubs-2017.html [Accessed 16 March 2018].

rozwijamy (2018), Co decyduje o sukcesie start-upów [What Determines Success of Start-Ups]. Available from www.rozwijamy.edu.pl/video/92-co-decyduje-o-sukcesie-start-upow [Accessed 16 March 2018].

\section{Corresponding author}

Anna Brdulak can be contacted at: anna.brdulak@wsb.wroclaw.pl 